\title{
USING BIM WITH THE LAST PLANNER® SYSTEM TO IMPROVE CONSTRAINTS ANALYSIS
}

\author{
Bernardo M. Etges' ${ }^{1}$, Raquel H. Reck², Marcus T. Fireman ${ }^{3}$, \\ Jerusa L. Rodrigues ${ }^{4}$, and Eduardo L. Isatto ${ }^{5}$
}

\begin{abstract}
Studies have shown that there are flaws in the implementation of the Last Planner ${ }^{\circledR}$ System, mainly concerning the use of medium-term planning in construction companies. Among the main related problems, we highlight the difficulty that the management team has in being able to identify constraints sufficiently in advance so that they can be removed. This would avoid interruption of service fronts and a jump in losses due to making-do. In this context, BIM is seen in this paper as a modeling environment of activities constraints that can help to overcome these deficiencies because, in addition to addressing the spatial issues of the undertaking, it can also hold information about the different construction elements, such as information about the unavailability of necessary prerequisites for starting or continuing the service. This article discusses the potential for inserting BIM into the medium-term and short-term planning of construction companies when such a plan is based on the Last Planner ${ }^{\circledR}$. For this purpose, planning data of five case studies from three different companies have been analyzed in two phases: (i) explain which categories of constraints identified in medium-term planning could be modeled in BIM; (ii) examine the percentage of work packages elaborated in short-term planning meetings could be modeled in BIM. Based on this analysis, regarding the constraints modelling in medium-term planning, it is cocluded that the BIM model with Last Planner ${ }^{\circledR}$ System can support to identifiy and remove constraints in a more agile and efficient way. Great potential for modeling medium-term constraints and of short-term packages occurs mainly for those that refer to Projects, Equipment, Work Safety and Materials.
\end{abstract}

\section{KEYWORDS}

BIM, lookahead planning, Last Planner® System (LPS)

1 PhD Cand., Building Innov. Research Unit (NORIE), Fed. Univ. of Rio Grande do Sul (UFRGS), Porto Alegre, RS, Brazil, +55 51 33083518, bernardo.m.etges@gmail.com, orcid.org/0000-0002-3037-5597

2 PhD Cand., Building Innov. Research Unit (NORIE), Fed. Univ. of Rio Grande do Sul (UFRGS), Porto Alegre, RS, Brazil, +55 51 33083518, raquelreck@gmail.com, orcid.org/0000-0003-1928-3461

3 PhD Cand., Building Innov. Research Unit (NORIE), Fed. Univ. of Rio Grande do Sul (UFRGS), Porto Alegre, RS, Brazil, +55 51 33083518, marcusctf@gmail.com, http://orcid.org/0000-0001-5843-4715

4 Master Student, Building Innov. Research Unit (NORIE), Fed. Univ. of Rio Grande do Sul (UFRGS), Porto Alegre, RS, Brazil, +55 51 33083518, jerusa.lopes@gmail.com, orcid.org/0000-0002-0514-0753

5 Associate Professor, School of Engineering, Building Innovation Research Unit (NORIE), Federal University of Rio Grande do Sul (UFRGS), Porto Alegre, Brazil, isatto@ufrgs.br, orcid.org/0000-0002$\underline{0851-8790}$ 


\section{INTRODUCTION}

Ever since Ballard (1994) introduced the Last Planner ${ }^{\circledR}$ System (LPS), it has been widely implemented by construction companies who seek to improve the reliability of production at construction sites. Several authors (Ballard, 1997; Ballard, 2000; Hamzeh, 2012; Pikas et al., 2012; Salvatierra et al., 2015; Al Hattab et al., 2017) have pointed out that one of the main elements that make up the LPS is medium-term planning, the main objective of which is to protect the workflow of the service fronts by necessarily having to be able to identify and remove constraints on the conduct of activities.

Despite the proven importance of applying medium-term planning, empirical studies have shown that failures to do so have led to jumps in wastes emerging in day-to-day production, whether due to labor force being left idle, to rework, to making-do, unfinished works, and so on (Bortolazza; Formoso, 2006; Kemmer et al., 2007; Fireman et al., 2013; Leão et al., 2014; Ibarra et al., 2016, Hamzeh et al., 2012). Angelim et al. (2020) recently conducted a study based on a systematic literature review that identified that one of the major shortcomings when applying medium-term planning lies precisely in the difficulty of identifying and removing constraints in advance (Angelim et al., 2020).

In Pikas et al. (2012) justifications for this failure can be identified, since the authors suggest that due to the large number of prerequisites that must be satisfied in order to perform an activity in Construction, the managers of works spend a lot of effort in the process of identifying and removing constraints, which makes the process slow and ineffective. This is, in fact, understandable, considering that carrying out an activity in civil Construction is influenced by the configuration of at least seven prerequisites (Koskela, 2004): (a) the project; (b) materials and components; (c) labor force; (d) equipment; (e) space; (f) interdependent tasks; and (g) external conditions.

In this regard, the joint application of BIM (Building Information Modeling) with LPS has been strongly suggested as a way to assist and streamline the process of identifying and removing constraints (Angelim et al., 2020; Fireman et al., 2013; Ibarra et al ., 2016; Sacks et al., 2012). BIM represents the components of the enterprise by means of digital objects that carry graphic geometry and information, as well as parametric rules (objectoriented language) that allow them to be manipulated intelligently. As a result, the model of the product will be a common source for all project participants throughout its life cycle, thereby improving communication about the product and the construction process (Leinonen et al., 2003).

This paper sets out to analyze how integrating BIM with the LPS system can enable constraints in medium-term planning to be identified and removed in a more agile and efficient way. Then, it is analyzed if the BIM could be integrated into the process of shortterm planning, since the work packages could be modeled, and thus, to map opportunities for improving the use of the LPS with BIM.

For this purpose, planning data of five case studies from three different companies have been analyzed in two phases: (i) explain which categories of constraints identified in medium-term planning could be modeled in BIM; (ii) examine the percentage of work packages elaborated in short-term planning meetings could be modeled in BIM.

\section{BIM AND LPS}

Over the years, many papers related the synergy between BIM and Lean. A detailed study was carried out by Sacks et al. (2010), which found 56 unique interactions between BIM functions and Lean construction processes. Also, the study found empirical evidence from 
past and ongoing construction projects to support these interactions. Furthermore, Harris et al. (2013) present a matrix interacting 4D BIM treading applications, from Heesom and Mahdjoubi (2004), and the five criteria for quality assignments, from Ballard and Howell (1998). The result was 23 potentially beneficial interactions that were validated in a case study conducted in a hospital project in Southern California. The potential interaction of Sacks et al. (2010) and Harris et al. (2013) are understood as a framework to direct future studies. However, empirical studies have to be held to validate these interactions, and new ones can be found in practical studies.

Thus, Alves and Britt (2011) present an empirical study with a general contractor to improve the lookahead planning process of a large healthcare facility in California by documented constraints and make them available in real-time. However, the BIM was not used for planning the workflow, because the model was too big and having a BIM specialist to attend multiple planning meetings did not prove feasible for the model to be frequently used in planning meetings (Alves; Britt, 2011). The result was that some constraints could not be anticipated until trades started working and required a very dynamic management system to address their needs (Alves; Britt, 2011).

In this sense, some software was developed to manage the synchronization of the planning process and BIM manipulation in an LPS environment (Sriprasert; Dawood, 2002; Sacks et al., 2012; Heigermoser et al., 2019; McHugh et al., 2019), a framework was proposed to effectively management constraint with the use of BIM, barcode, and Radio Frequency Identification (Wang et al., 2015); and a framework of integrated quality and production control on-site with the use of mobile devices was asses (Leão et al., 2014; Ibarra et al ., 2016). However, the LPS parameters have to be highlighted to understand if it can be BIM detected or not.

Sriprasert and Dawood (2002) sort the constraint in physical constraints (i.e., technological dependencies and temporal/spatial aspects) and enabler constraints (i.e., availability of information and resources). The physical constraints are BIM detected, and enabler constraints are only identified by the LPS process. This argument shows that not all the constraints at lookahead can be BIM detected, and some are necessary to be filled out by other sources of information and even by the experience of the manager's team. Bhatla and Leite (2012) use the lookahead meeting to conduct the clash process of the BIM model. A framework was proposed, and the clash process of the models was done during lookahead meetings (Bhatla; Leite, 2012). Even though the lookahead planning process relies on the design specification of the BIM models, another type of constraint needed to be addressed in the process of identifying the constraint. Hence, Bortolini et al. (2015) and Peñaloza et al. (2016) use the BIM model of two engineering-to-order construction site to model non-value activities of operations, and material storage on-site and identify logistics constraints in lookahead planning meetings. In logistics modeling, it is necessary to shape workspaces. Riley (2003) defines four appropriate spaces: (a) physical workspace, (b) areas for storing materials, (c) paths for the movement of materials, and (d) access points to unload materials on floors of the building under Construction or at production units. The automatic detection of potential conflicts between workspaces, storage areas and paths of different work fronts represents the central objective of the 4D modeling process since it allows the sequence of work to be evaluated over time (Riley, 2003).

Additionally, Toledo et al. (2016) compare two case studies (one using only LPS and the other using LPS and BIM) to proof of the benefits of the BIM-Lean planning framework. They use weekly and lookahead planning meetings analyses, design requests 
for information (RFI), and LPS metrics. Even without the use of BIM models in lookahead planning meetings, the coordinated use of LPS and BIM generates an increase in Percentage of Plan Completion, a decrease in reasons for non-compliance, a shortening of the meeting durations, and a reduction in the total number of design RFI (Toledo et al., 2016). This example shows that the benefits are effective planning meetings and improvement of communication project by the combination of BIM and LPS.

\section{RESEARCH METHOD}

The analysis presented in this paper is based on multiple exploratory case studies. According to Yin (2003), the case study is a strategy of research appropriated to answer "How" or "Why" questions, generally related to contemporary events in which the investigator has little or no control. At this point, the objective of this research is to understand:

"Why BIM can contribute to the analysis of constrains in the Last planner system?"

In this research, planning data of five case studies from three different companies have been analyzed. The criteria for selecting the studies were based on: (a) each one of them has a planning and control method based on the elements of LPS; (b) has a history of implementing lean tools; (c) provide access to information; (d) the companies are in the initial stage of implementing BIM. Table 1 presents a description of each case study.

Yet, it is important to highlight that the authors of this article, have had previous experience and have engaged actively in the cases presented, either as a member of the company's technical team (Case 1, 2, 3 and 4) or as external consultants in the Case 5. Thus, at least one of the author authors took part in the production planning and control routines of the four construction sites.

Table 1: Description of the five case studies and the three companies

\begin{tabular}{|c|c|c|c|c|}
\hline & Market & Case Study & Built area & Characteristics \\
\hline \multirow[t]{2}{*}{$\begin{array}{l}\text { Construction } \\
\text { Company } 1\end{array}$} & \multirow{2}{*}{$\begin{array}{l}\text { Residential } \\
\text { High-, } \\
\text { Middle- and } \\
\text { Low-income }\end{array}$} & Case 1 & $13.505,67 \mathrm{~m}^{2}$ & $\begin{array}{c}127 \text { residential units } \\
1 \text { tower block } \\
2 \text { stores }\end{array}$ \\
\hline & & Case 2 & $80.902,05 \mathrm{~m}^{2}$ & $\begin{array}{c}576 \text { residential units } \\
4 \text { tower blocks }\end{array}$ \\
\hline \multirow{2}{*}{$\begin{array}{c}\text { Construction } \\
\text { Company } 2\end{array}$} & \multirow{2}{*}{$\begin{array}{l}\text { Residential } \\
\text { High-, } \\
\text { Middle- and } \\
\text { Low-income } \\
\text { and } \\
\text { Commercial }\end{array}$} & Case 3 & $10.150,67 \mathrm{~m}^{2}$ & $\begin{array}{l}\text { Commercial }+ \text { hotel } \\
1 \text { tower block with } 168 \text { private } \\
\text { units }\end{array}$ \\
\hline & & Case 4 & $32.405,82 \mathrm{~m}^{2}$ & $\begin{array}{c}\text { Commercial+health } \\
1 \text { tower block with } 423 \text { private } \\
\text { units }\end{array}$ \\
\hline $\begin{array}{l}\text { Construction } \\
\text { Company } 3\end{array}$ & $\begin{array}{l}\text { Metallic } \\
\text { Construction } \\
\text { System }\end{array}$ & Case 5 & $24.695 \mathrm{~m}^{2}$ & $\begin{array}{c}\text { Expansion of Airport (Pier, } \\
\text { Processor, Boarding bridges } \\
\text { and Annexes) }\end{array}$ \\
\hline
\end{tabular}




\section{DATA COLLECTION AND ANALYSIS}

The main sources of evidence used in the case studies were typically qualitative and contemplated the following analyzes: (a) constraints presented in the medium-term planning; (b) work packages from the short-term planning meetings; (c) documents related to the production planning and control model. Table 2 summarizes the data used in the analysis, which comprises a database with 1242 work packages, 217 medium-term constraints.

The work method consists of two phases: (i) analyze which categories of constraints identified in medium-term planning could be modeled in BIM; (ii) examine the percentage of work packages elaborated in the short-term plan could be modeled in BIM.

In the first phase, a database was initially created with the constraints identified in the medium-term planning of the construction works, as described in Table 2. Subsequently, each constraint was categorized according to its relation to: Material, Labor force, Equipment, Security, Project, and Planning. Finally, the researchers carried out a qualitative classification section of the constraints regarding the possibility of modeling them.

Table 2: Data collection at the five case studies

\begin{tabular}{|c|c|c|c|c|}
\hline Case Study & Typology & $\begin{array}{c}\text { Constructive } \\
\text { Phase }\end{array}$ & Constraints & $\begin{array}{c}\text { Analysis of } \\
\text { work-packages }\end{array}$ \\
\hline Case 1 & Residential & Infrastructure & 22 & 91 \\
\hline Case 2 & Residential & All services & 12 & 815 \\
\hline Case 3 & Commercial & All services & - & 297 \\
\hline Case 4 & Commercial & Finishings & 51 & - \\
\hline Case 5 & Industrial & Superstructure & 132 & 39 \\
\hline \multicolumn{2}{r}{} & Total & 217 & $\mathbf{1 2 4 2}$ \\
\hline
\end{tabular}

In the second phase, initially was created a database with the work packages planned in the short-term meetings. These packages were classified according to which construction stage (masonry, infrastructure, finishing, etc..). Finally, the researcher carried out a qualitative classification section of the work-packages regarding the possibility of modeling them using the same criteria of the first phase.

It is important to highlight that in both phases, the qualitative classification was done in a focus group, composed of the four authors. Yet, when sometimes there was a disagreement, a consensus was reached.

\section{RESULTS}

\section{ANALYSIS OF MEDIUM-TERM DATA}

From the data on medium-term constraints collected at the 4 construction works, a matrix could be created to analyze which categories of constraints by type of construction works are best suited to being modeled in the medium-term (Figure 1). 


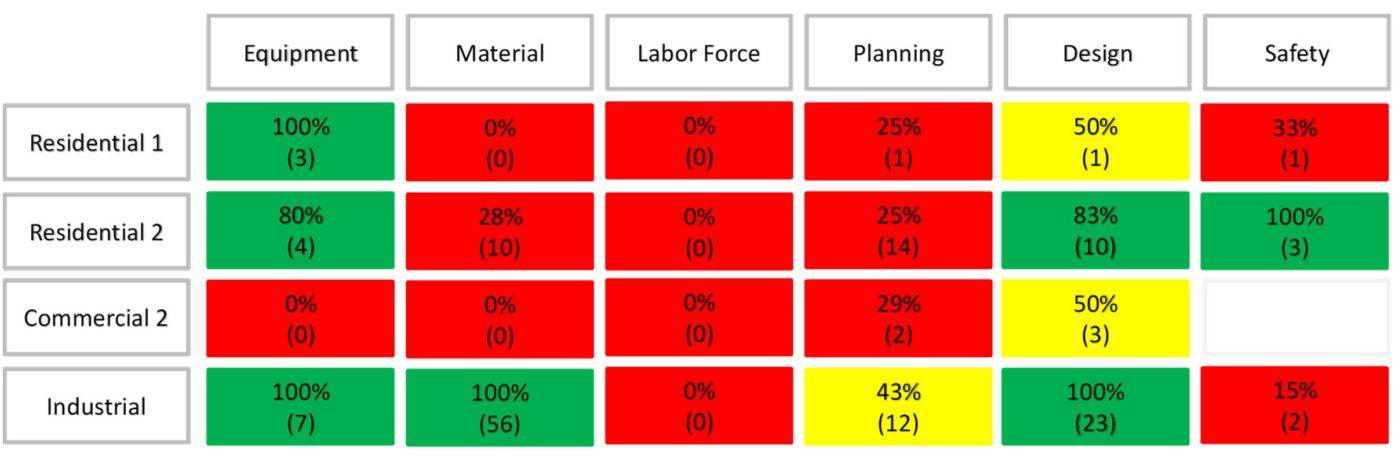

Figure 1: Analysis of identified constraints categories that can be modeled by type of construction work

Considering the differences between typology and stage of the construction work, the matrix enabled the following analyzes to be made regarding the categories. Constraints categorized in Equipment: They have an excellent opportunity to be modeled in the medium-term. Examining both residential and industrial construction works identified that between 80 to $100 \%$ of the medium-term constraints in this category could be modeled, e.g., dimensioning which type of crane or platform should be contracted for industrial construction works or up to what height the boom of the concrete pump should reach for concreting. It is important to point out that it was only in the Commercial 2 construction works that the constraints identified could not be modeled, since, as the data referred to the finishing stage, many of the definitions about the equipment that involves some type of modeling had already been made in the previous steps. In the finishing stage, the equipment constraints refer mainly to the action of checking whether scaffolding is correctly assembled or monitoring contractual issues that they cause to be raised.

Regarding the Material constraint, the data analysis showed a particular contrast concerning the possibility of modeling between the different types of construction works and the stage of these works. In industrial works, with an engineer-to-order type of production, there is the possibility of modeling the constraints categorized as material, since each structural element has its own characteristic, and monitoring and tracking its manufacturing and shipping status is a key constraint to the performance of the Construction works. In residential and commercial works, most materials do not need to be modeled since they are more standardized. Except for the materials referring to sanitary porcelain and metals that need to be defined and consequently analyzed, the correct position needs to be analyzed.

Planning Constraints include resource programmings, such as access planning for moving and positioning equipment and provisional installations. In this regard, it was found that only $25 \%$ to $40 \%$ of the constraints in this category can be modeled and refer mainly to the planning of accesses and physical flows. In the industrial works where the superstructure is prefabricated, the tendency is that the modeling of constraints in this category is more likely than in residential and commercial construction works.

As for the Project constraints, the potential for modeling them is clear, Depending on the stage and type of construction works, the percentage of constraints increases, as is the case with the residential 2 construction works, for which the data represent all stages of the Construction works, and the industrial work, for which there is a $100 \%$ possibility of 
being able to model the project constraints, thus letting the project manager have information on any design changes in the project being updated in the model.

Finally, the Security constraints show that in vertical works, they enable modeling of collective protections and their interface with façade elements and the method of executing facades and the structure. Another interesting analysis that can be made is that constraints in this category tend to be analyzed at different stages or moments of the construction work, which reflects the difference between the percentage of constraints that can be modeled in residential 2 in relation to Residential 1 and Commercial 2. In industrial works, these constraints tend to be less analyzed, due to the short cycle of the stages of the works and the modularization of the construction work, which already includes collective protections since the design stage.

\section{ANALYSIS OF THE SHORT-TERM DATA}

Figure 2 presents a graph with the percentage of packages that can be modeled in the short term concerning the stage and type of work. It is important to point out, one limitation of the current paper, that there are works performed by different companies and different moments and project typologies; however, it is possible to highlight:

(a) Internal coating: It can be considered that on average $50 \%$ of the packages in this category that are prepared in the short term can be modeled;

(b) External coating: Unlike the internal coating, on average, 38\% of short-term packages in this category can be modeled. This is since many short-term packages involve support structures assembly (scaffolding installations, for example), which are important for medium-term analysis, do not require weekly monitoring;

(c) Drywall and temporary installations: These are work packages with a greater potential to be modeled in the short term. The Drywall category has an average of 59\% modeled packages, while the temporary installations (shed, bathrooms, living area) has an average of $75 \%$. Modeling temporary installations packages is necessary to allow analyzing if there will be any restriction impact in materials, employees or equipment flow;

(d) Infrastructure and Suprastructure: Packages considering the infrastructure category showed a more homogeneous rate between the different analyzes projects, demonstrating that about $35 \%$ of the packages can be modeled. On the other hand, superstructure packages showed a great deviation between the comparison of the project: while in the industrial project, the packages in great majority should be modeled (about 64\%), in residential and commercial works did not exceed 37\%. In industrial works, the superstructure requires a great analysis of the movement of equipment, materials, and people since the physical flow in this type of work is more dynamic, and the residential and commercial projects are designed with conventional reinforced concrete. 


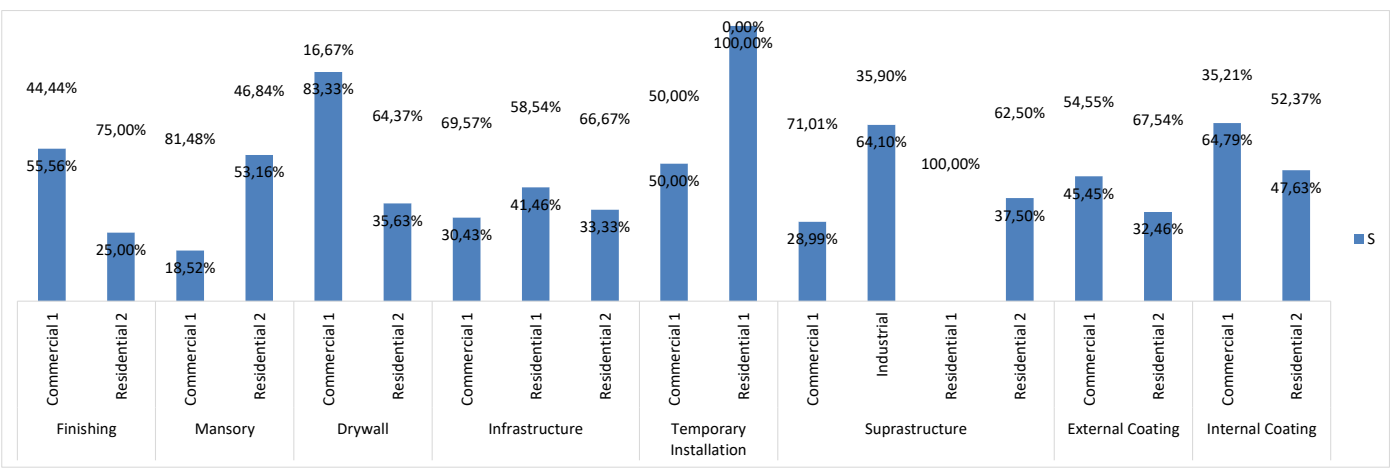

Figure 2: Analysis of packages that can be modeled in a short-term plan considering by type of construction work

Analyzing the data on the causes of the non-completion of activities as planned, it is still possible to understand whether or not that work package planned for execution at week level could be modeled. From this analysis, it can be seen that every execution problem in the Project category can be modeled. The Access category can also be modeled as it represents the interference of the stages of the product, pieces of equipment, and workflows. In the Materials category, only causes of lack of material due to losses above those expected could be modellable, since we would have more precise quantitative estimates of the materials. As for the equipment, a detailed study in the BIM model could avoid the causes of acquiring inappropriate equipment for the activity or bad dimensioning. As for the Safety category, delay in integration are not adjustable, but stoppages due to lack of collective protection. The categories of the Labor force, Other (mainly weather conditions), and Client are not configurable.

The joint analysis of medium-term constraints and causes of short-term noncompletion are convergent, with a high capacity for modeling the categories of project, equipment, access, and Materials according to the stage of the construction work and of the safety stage concerning physical structures of collective protection and workflow.

\section{CONCLUSIONS}

Considering the main objective of the current paper in undestanding why BIM contribute to the analysis of constrains in the LPS and that the metological approach was conduced in two mains phases: (i) constraints identified in medium-term planning that could be modeled in BIM (based on 217 constraints collected); and (ii) the percentage of work packages elaborated in short-term planning meetings that could be modeled in BIM (baded on 1242 packages data base), we may conclude that the integration of BIM with LPS can let constraints in medium-term planning be identified and removed in a more agile and efficient way. By using the BIM 4D model to support the modeling of constraints, it could be seen that the use of the BIM model throughout the PPC process brings benefits to the planning of the Construction project.

Great potential for modeling medium-term constraints and causes of short-term in the BIM model was identified. This occurs mainly for those that refer to Projects, Equipment, Work Safety (in the case of collective protections), Materials (mostly in engineer-to-order works).

It is also possible to verify that the use of BIM can be different in the planning horizons defined by the LPS. Considering the focus of the study in medium and short-term plans 
it can be seen that in the medium term, BIM can be used to allow simulations and visualizations of the position of teams, equipment, and sequence of activities to be simulated and visualized and to understand and visualize workflows. In the short term, using BIM enables packages to be visualized in greater detail, thus facilitating their correct definition, and can let different management systems come under integrated control. We highlight the use of BIM in planning meetings both in the medium term (Construction Company 1) and in the short-term (Construction Companies 1 and 2) since the model allows participants involved to have a common interpretation of the strategies defined for the enterprise.

As future studies, it is suggested the common use of BIM model with LPS by integrating the modeling of the attributes and constraints identified for a comparative case study that lets the potential gains be measured.

\section{REFERENCES}

Al Hattab, M., Zankoul, E., and Hamzeh, F. R. 2017. "Near-real-time optimization of overlapping tower crane operations: a model and case study." Journal of Computing in Civil Engineering, vol. 31, no. 4.

Alves, T. C. L. and Britt, K. 2011. "Working to Improve the Lookahead Plan." Proc. $19^{\text {th }}$ Ann. Conf. Int. Group for Lean Construction, pp. 281-290, Lima, Peru.

Angelim, V. L., Alves, T. Da C. L., Lima, M. M. X. De, Barros Neto, J. De P. 2020, "Planejamento de médio prazo: panorama de sua aplicação na construção civil." Ambiente Construido, Porto Alegre, Brazil, v. 20, n. 1, p. 87-104.

Ballard, G. 1994. "The Last Planner." Proceedings of the Spring Conference Northern California Construction Institute Publication. Monterey.

Ballard, G. 2000. The Last Planner ${ }^{\circledR}$ system of production control. PhD Diss., School of Civil Engineering, The University of Birmingham, UK.

Ballard, G. 1997. "Lookahead Planning: The Missing Link in Production Control." Proc. $5^{\text {th }}$ Annual Conference of the International Group for Lean Construction, Gold Coast, Australia.

Ballard, G., Howell, G. 1998. "Shielding Production: An Essential Step In Production Control." Journal of Construction Engineering and Management, V. 124, N. 1, pp. $18-24$.

Bhatla, A. and Leite, F. 2012. "Integration Framework of BIM With the Last Planner System." Proc. $20^{\text {th }}$ Ann. Conf. Int. Group for Lean Construction, pp. 10, San Diego, USA.

Bortolini, R., Shigaki, J. S.-I., and Formoso, C. T. 2015, Site Logistics Planning and Control Using 4d Modeling: A Study In A Lean Car Factory Building Site. In: Annual Conference of The International Group For Lean Construction, 23. V. 55, pp. 361370. Perth, Australia.

Bortolazza, R. C. and Formoso, C. T. 2006. "A Quantitative Analysis of Data Collected From the Last Planner System in Brazil." Proc. 14th Ann. Conf. Int. Group for Lean Construction, Santiago, Chile, pp. 625-635

Fireman, M.C.T., Formoso, C.T., and Isatto, E.L. 2013. "Integrating production and quality control: monitoring making-do and informal work packages." Proc $21^{\text {st }}$ Ann. Conf. Int. Group for Lean Construction, pp. 515-525, Fortaleza, Brazil.

Hamzeh, F., Ballard, G., and Tommelein, I. D. 2012. "Rethinking Lookahead Planning to Optimize Construction Workflow." Lean Construction Journal, pp. 15-34. 
Harris, B., Da, T., Alves, C. L. 2013. "Enabling Lean with It 4d Building Information Modeling And Field Operations: An Exploratory Study." Proc $21^{\text {st }}$ Ann. Conf. Int. Group for Lean Construction, pp. 811-820. Fortaleza, Brazil.

Heesom, D., Mahdjoubi, L. 2004. "Trends of 4D CAD applications for construction planning." Construction Management and Economics, v. 22, n. 2, p. 171-182.

Heigermoser, D., García, B., Soto, D., et al. 2019. "Automation in Construction BIMbased Last Planner System tool for improving construction project management." Automation in Construction, v. 104, n. May, p. 246-254. Elsevier.

Ibarra, J.V., Formoso, C.T., Lima, C., Mourão, A., and Saggin, A. 2016. "Model for integrated Production and Quality Control: Implementation and Testing Using Commercial Software Applications." Proc 24th Ann. Conf. Int. Group for Lean Construction, Boston, USA, 20-22.

Kemmer, S. L., Heineck, L. F., Novaes, M. V., Mourao, C. A. M. and Alves, T. C. 2007. "Medium-Term Planning: Contributions Based on Field Application." In: Pasquire, C.L, and Tzortzopoulos, P. Proc $15^{\text {th }}$ Ann. Conf. Int. Group for Lean Construction, East Lansing, Michigan, USA, pp. 509-518.

Koskela, L. 2004. "Making-do - the Eighth Category of Waste." Proc $12^{\text {th }}$ Ann. Conf. Int. Group for Lean Construction, Denmark.

Leão, C. F., Formoso, C. T. and Isatto, E. L. 2014. "Integrating Production and Quality Control with the Support of Information Technology.” In: Kalsaas, B. T., Koskela, L. and Saurin, T. A., Proc 22 ${ }^{\text {nd }}$ Ann. Conf. Int. Group for Lean Construction, Oslo, Norway, pp. 847-858.

Leinonen, J. et al. 2003. "New construction management practice based." In: $4 D C A D$ and Visualization in Construction: developments and applications. A. A. Balkema Publishers, p. 75-99.

Mchugh, K., Dave, B., and Craig, R. 2019. "Integrated Lean and BIM Processes for Modularised Construction - A Case Study." Proc $27^{\text {th }}$ Ann. Conf. Int. Group for Lean Construction, pp. 227-238, Dublin, Ireland.

Peñaloza, G. A., Viana, D. D., Bataglin, F. S., Formoso, C. T., Bulhões, I. R. 2016. "Guidelines for Integrated Production Control in Engineer-To-Order Prefabricated Concrete Building Systems: Preliminary Results." Proc $24^{\text {th }}$ Ann. Conf. Int. Group for Lean Construction, pp. 103-112, Boston, USA.

Pikas, E., Sacks, R., and Priven, V. 2012. "Go or No-Go Decisions at the Construction Workface: Uncertainty, Perceptions of Readiness, Making Ready and Making-Do." In: Tommelein, I. D. and Pasquire, C. L., Proc $20^{\text {th }}$ Ann. Conf. Int. Group for Lean Construction, San Diego, USA, 18-20.

Riley, D.2003. "The Role of 4D Modeling in Trade Sequencing and Production Planning." In: $4 D$ CAD and Visualization in Construction: developments and applications. Reston, VA: A. A. Balkema Publishers. p. 1029-1034.

Sacks, R., Koskela, L., Dave, B. A., and Owen, R. 2010. "Interaction of Lean and Building Information Modeling in Construction." Journal of Construction Engineering and Management, v. September, n. September, p. 968-980.

Sacks,R., Barak, R., Belaciano, B., Gurevich, U., and Pikas, E. 2012. "KanBIM Workflow Management System: Prototype implementation and field testing." Lean Construction Journal, pp. 19-35.

Salvatierra, J.L., Alarcón, L.F., López, A., and Velásquez, X., 2015. "Lean Diagnosis for Chilean Construction Industry: Towards More Sustainable Practices." In: Proc. $23^{\text {rd }}$ Ann. Conf. of the Int'l. Group for Lean Construction, Perth, Australia. 
Sriprasert, E., Dawood, N. 2002. "Next Generation of Construction Planning and Control System: The Lewis Approach." In: Proc 10 $0^{\text {th }}$ Ann. Conf. Int. Group for Lean Construction, pp. 1-12, Gramado, Brasil.

Toledo, M., Olivares, K., and González, V. 2016. "Exploration of A Lean-BIM Planning Framework: A Last Planner System and Bim-Based Case Study." In: Proc $26^{\text {th }}$ Ann. Conf. Int. Group for Lean Construction, pp. 3-12, Boston, USA.

Wang, J., Shou, W., Wang, X. 2015. "A framework of total constraint management for improving work flow in liquefied natural gas construction." Proc. Annual Association of Researchers in Construction Management Conference, 31. p. 803-812.

Yin, R. K. 2003. Case Study Research: Design and Methods. Thousand Oaks, California: Sage Pubs., p. 94. 
Using BIM with the Last Planner® System to Improve Constraints Analysis

This page was intentionally left blank. 